\title{
Electrographic Seizures and New Recurrent Excitatory Circuits in the Dentate Gyrus of Hippocampal Slices from Kainate-Treated Epileptic Rats
}

\author{
Jean-Pierre Wuarin and F. Edward Dudek \\ Department of Anatomy and Neurobiology, Colorado State University, Fort Collins, Colorado 80523
}

\begin{abstract}
Mossy fiber sprouting has been proposed to lead to new excitatory connections between dentate granule cells, which in turn cause electrographic seizures. We tested this hypothesis in hippocampal slices from rats made epileptic by kainate injections. The Timm's histological method revealed intense staining of the inner molecular layer in slices from all kainatetreated rats. In bicuculline $(10 \mu \mathrm{M})$ and $6 \mathrm{~mm}\left[\mathrm{~K}^{+}\right]_{\mathrm{o}}$, antidromic stimulation of the granule cells evoked bursts of population spikes superimposed on long-lasting negative shifts in all slices tested from all kainate-treated rats. Long-duration (2-47 sec), seizure-like bursts with tonic and clonic components occurred spontaneously $(53 \%)$ or in response to antidromic stimulation (81\%). Under identical conditions, prolonged bursts were never seen in slices from controls or from kainate-injected rats 2-4 d after treatment. Glutamate microdrops applied in the granule cell layer evoked abrupt increases in the frequency of excitatory
\end{abstract}

Hippocampal sclerosis is a frequent occurrence in patients with temporal lobe epilepsy. It is characterized by neuron loss, particularly in the hilar and CA1 and CA 3 areas, and by sprouting of granule-cell mossy fibers in the inner molecular layer (Margerison and Corsellis, 1966; Ben-Ari, 1985; de Lanerolle et al., 1989; Sutula et al., 1989; Babb et al., 1991; Houser, 1992). The possible link between neuron loss after status epilepticus and subsequent epilepsy is a fundamental problem (Represa et al., 1994; Larner, 1995). Although the effects of kainate treatment can be variable, kainate injections induce repeated convulsive seizures followed, after a seizure-free period, by spontaneous generalized seizures (Nadler, 1981; Ben-Ari, 1985; Franck, 1993; Sperk, 1994). It also produces neuronal loss and mossy fiber sprouting in the hippocampus. We used this model of temporal lobe epilepsy to test the hypothesis that mossy fiber sprouting forms new recurrent excitatory pathways that enhance seizure susceptibility in the dentate gyrus.

Tauck and Nadler (1985) were the first to show data suggesting that mossy fiber sprouting could form recurrent excitatory circuits. In kainate-treated rats, they found that antidromic electrical stimulation of granule cells could evoke multiple population spikes and that the antidromic response could be potentiated by a conditioning stimulus. Both abnormalities were correlated to the intensity of mossy fiber sprouting. Sloviter (1992) subsequently

\footnotetext{
Received Feb. 2, 1996; revised April 22, 1996; accepted April 26, 1996.

This research was supported by National Institutes of Health Grant NS16683. We thank J. Welton for technical assistance and A. Bienvenu for word processing.

Correspondence should be addressed to Dr. F. Edward Dudek, Department of Anatomy and Neurobiology, Fort Collins, CO 80523.

Copyright (C) 1996 Society for Neuroscience $0270-6474 / 96 / 164438-11 \$ 05.00 / 0$
}

postsynaptic potentials (EPSPs) in two thirds of the cells tested. Glutamate microstimulation was effective at several sites in the granule cell layer but ineffective in the hilus. The proportion of granule cells responding to local application of glutamate by an increase in EPSPs was higher in slices with long bursts $(80 \%$ with bursts of $>3 \mathrm{sec}$ ) than in slices with shorter bursts (33\% with bursts of $<3 \mathrm{sec}$ ). Glutamate microstimulation did not affect EPSPs in granule cells from control preparations. These results support the hypothesis that kainate-induced mossy fiber sprouting forms new excitatory connections between granule cells and can lead to increased seizure susceptibility in the dentate gyrus.

Key words: epilepsy; hippocampus; granule cell; kainic acid; mossy fibers; sprouting; seizure-like bursting; glutamate microstimulation

suggested that sprouting is aimed preferentially at inhibitory basket cells, therefore reestablishing normal levels of inhibition to the granule cells. His conclusions were based on the observation that stimulation of the perforant path evoked multiple population spikes 2-4 d after kainate treatment and that the response seemed normal after 2-4 months. On the basis of earlier work on recurrent excitatory circuits in the CA3 area (Miles and Wong, 1983, 1986, 1987; Christian and Dudek, 1988a), Cronin and colleagues (1992) hypothesized that new recurrent excitatory circuits among granule cells would be masked by recurrent inhibition. In conditions of reduced inhibition, they found that electrical stimulation of the hilus could evoke bursts in granule cells recorded in slices with mossy fiber sprouting. These bursts, however, were of short duration, unlike prolonged seizure-like events, and electrical stimulation of the hilus provided only indirect support for synaptic connections between granule cells.

In the present study, we used multiple injections of kainate, which produced a more consistent model, and monitored the behavior of the animals periodically until the day of experimentation. We prepared slices for experimentation only after the animals had had many seizures during a period of several months. All of the experiments were performed in the presence of bicuculline to eliminate a possible masking effect of local inhibition, and $\left[\mathrm{K}^{+}\right]_{\mathrm{o}}$ was raised from 3 to $6 \mathrm{~mm}$ to increase the potential for multisynaptic circuit interactions. In these conditions, we tested two interrelated hypotheses: (1) slices with mossy fiber sprouting have increased seizure susceptibility when $\mathrm{GABA}_{\mathrm{A}}$-receptormediated inhibition is blocked, and (2) these same slices have new recurrent excitatory circuits. We found that mossy fiber sprouting was associated with (1) prolonged, seizure-like events both spon- 
taneously and in response to hilar (i.e., antidromic) stimulation, and (2) pronounced increases in the occurrence of excitatory postsynaptic potentials (EPSPs) after specific stimulation of the granule cells with microapplication of glutamate in the granule cell layer.

\section{MATERIALS AND METHODS}

Kainate treatment. Adult male rats $(200-250 \mathrm{gm})$ were injected with kainate $(5 \mathrm{mg} / \mathrm{kg}$ in $150 \mathrm{~mm} \mathrm{NaCl}$, i.p.) every hour for up to $10 \mathrm{hr}$. Seizure intensity was evaluated using the scale described by Racine (1972). Generally, facial clonus, wet-dog shakes, and head nodding (stages 1-2) appeared after the second injection. Low-intensity tonic-clonic seizures, mostly of the forelimbs (stage 3), began after the third injection. Rearing and falling (stages 4-5) began after the fourth injection. Occasional episodes of circling and jumping were observed after the fourth injection. Recurrent convulsive seizures (stages 4-5) were observed for 4-6 hr after the fourth and fifth injection and then slowly subsided in most rats, even with more kainate injections. In rats with very frequent or continuous stages 4-5 seizures, we either skipped an injection or gave half the dose. The total dose per rat was $30-50 \mathrm{mg} / \mathrm{kg}$. Each animal had a minimum period of $6 \mathrm{hr}$ of recurring seizure activity before the treatment was stopped. Control rats were injected every hour with the vehicle (intraperitoneally) in parallel with the kainate-treated rats. All of the kainatetreated rats received subcutaneous injections of lactated Ringer's immediately after the treatment. Their hydration state was monitored during the following weeks, and lactated Ringer's injections were given as needed. The survival rate was $\sim 80 \%$. After the kainate treatment, the behavior of both control and kainate-treated rats was monitored for 4-10 $\mathrm{hr} /$ week during a period of several months to determine whether the treatment did induce chronic epilepsy. A detailed account of these results is in preparation (Patrylo and Dudek, unpublished observations). Briefly, all of the kainate-treated rats used in the present study showed frequent (several/day), recurrent seizures (stages 3-5) during the period of 4-13 months after kainate injections. Therefore, the kainate-treated rats used in the present study were 8-18 months old at the time they were euthanized, and they all had chronic epilepsy for several months. None of the control rats used in the present study showed any behavioral seizures.

Preparation of slices and recording. Kainate-treated and control rats were injected with pentobarbital sodium $(50 \mathrm{mg} / \mathrm{kg}$, i.p.), and their brains were removed quickly and immersed in ice-cold oxygenated perfusion solution containing (in mM): $124 \mathrm{NaCl}, 3 \mathrm{KCl}, 1.3 \mathrm{CaCl}_{2}, 26 \mathrm{NaHCO}_{3}, 1.3$ $\mathrm{MgSO}_{4}, 1.4 \mathrm{NaH}_{2} \mathrm{PO}_{4}$, and 11 glucose. The brains were then bisected sagittally and the two halves were glued, ventral side up, on the stage of a Vibratome (Campden Instruments). Slices, $500 \mu \mathrm{m}$ in thickness, were cut perpendicularly to the longitudinal axis of the hippocampus. The hippocampus and dentate gyrus were isolated from the rest of the tissue with knife cuts and transferred to an interface recording chamber (Haas et al., 1979). In the recording chamber, slices were thermoregulated $\left(\sim 32^{\circ} \mathrm{C}\right)$, oxygenated $\left(95 \% \mathrm{O}_{2} / 5 \% \mathrm{CO}_{2}\right)$, and perfused $(1.5 \mathrm{ml} / \mathrm{min})$ with the same solution used for the dissection, except $\left[\mathrm{K}^{+}\right]_{\mathrm{o}}$ was increased to $6 \mathrm{mM}$, and $10 \mu \mathrm{M}$ bicuculline (Sigma, St. Louis, MO) was added.

Intra- and extracellular recordings were performed with electrodes containing $2 \mathrm{M} \mathrm{K}^{+}$-acetate or $1 \mathrm{M} \mathrm{NaCl}$, producing tip resistances of 50-100 and 2-4 M $\Omega$, respectively. Granule cell impalements were obtained with a Nanostepper microdrive (Scientific Precision Instruments), using $4 \mu \mathrm{m}$ steps. Both intra- and extracellular data were recorded with an Axoclamp-2A amplifier (Axon Instruments, Foster City, CA), digitized at $22 \mathrm{kHz}$ with a Neuro-Corder (Neuro Data Instruments), and stored on video tapes. Off-line analysis was performed in part with pClamp 6 (Axon Instruments). Bipolar electrodes of Teflon-insulated platinum-iridium wire $(75 \mu \mathrm{m}$ in diameter) were positioned in the hilar area to stimulate granule cells antidromically (Fig. 1).

Glutamate microapplication. Glutamate (L-glutamic acid, Sigma) was dissolved in perfusion solution $(20 \mathrm{~mm})$. A Picospritzer (General Valve, Fairfield, NJ) was used to apply back pressure to patch pipettes $(2-4 \mu \mathrm{m}$ outer diameter) with tips coated with Sylgard (Dow Corning, Corning, NY). Microdrops (100-200 $\mu \mathrm{m}$ diameter) were formed at the tip of the pipette and stayed attached. They were then lowered on the surface of the slice under visual control. A stereomicroscope with a reticle $(20 \mu \mathrm{m}$ resolution) was used to measure microdrop diameters, place the microdrops in the selected locations, and measure the distances between sites of application and recording electrodes. Glutamate microdrops were first applied at a distance of $\sim 200 \mu \mathrm{m}$ from the point of entry of the recording electrode in the tissue. Subsequent applications were performed by

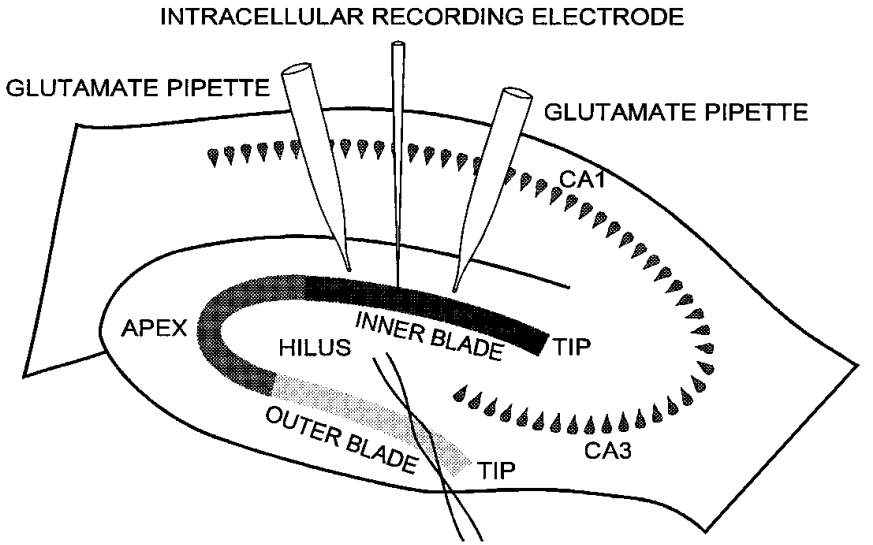

HILAR STIMULATING ELECTRODE

Figure 1. Diagram of hippocampal slice preparation and experimental configuration. The granule cell layer is shown divided into three regions: inner blade, apex, and outer blade. The electrode used for antidromic electrical stimulation of dentate granule cells is represented with its tip located in the region of the hilus. Pipettes for the application of glutamate microdrops (glutamate pipette) are shown positioned on both sides (tip and apex) of a recording electrode in the inner blade.

moving the pipette away from the recording electrode in $50 \mu \mathrm{m}$ steps. The sites closest to the recording electrode $(50-150 \mu \mathrm{m})$ were stimulated last. We divided the granule cell layer into three regions (i.e., inner blade, apex, and outer blade; see Fig. 1) to define the relative positions of microdrops and recording electrodes. The $\chi^{2}$ test for two independent variables was used to test the hypothesis that the presence or the absence of a response (i.e., increased excitatory input) to glutamate microstimulation was dependent on the duration of the electrically evoked extracellular burst.

Staining of mossy fiber sprouting. The Timm's histological procedure was used to label the zinc-containing mossy fiber boutons (Cronin et al., 1992). After completion of the electrophysiological experiments, slices were processed with the Timm's method for sulfide precipitation of zinc and counterstained with cresyl violet (Fig. 2).

\section{RESULTS}

\section{Granule cell passive properties}

No significant difference was found in the input resistance and resting membrane potential of granule cells recorded in slices from control and kainate-treated rats. Altogether, 47 granule cells were recorded in 26 slices from 15 kainate-treated rats with mossy fiber sprouting. The average cell input resistance was $63 \mathrm{M} \Omega( \pm$ $3.4, n=39)$, and the average resting membrane potential was -72 $\mathrm{mV}( \pm 1.1, n=41)$. Twenty-one granule cells were recorded in 18 slices from eight control rats. The average input resistance was 61 $\mathrm{M} \Omega( \pm 4.6, n=20)$, and the average resting membrane potential was $-72 \mathrm{mV}( \pm 1.3, n=19)$. The average resting membrane potential was more depolarized than what has been reported in previous studies (Cronin et al., 1992), probably because of the presence of $6 \mathrm{~mm}\left[\mathrm{~K}^{+}\right]$in the perfusion solution.

\section{Antidromic electrical stimulation of granule cells from control rats}

Extracellular field-potential recordings of antidromic activation of the dentate granule cells were obtained in 39 slices from 14 control rats. Even in conditions of decreased inhibition and increased excitability (i.e., $10 \mu \mathrm{M}$ bicuculline and $6 \mathrm{~mm}\left[\mathrm{~K}^{+}\right]_{\mathrm{o}}$ ), electrical stimulation of the hilar region usually evoked only one population spike in the granule cell layer (Fig. 3A1-A3). The amplitude of the antidromically induced population spike was dependent on the stimulus intensity. Stimuli of supramaximal 


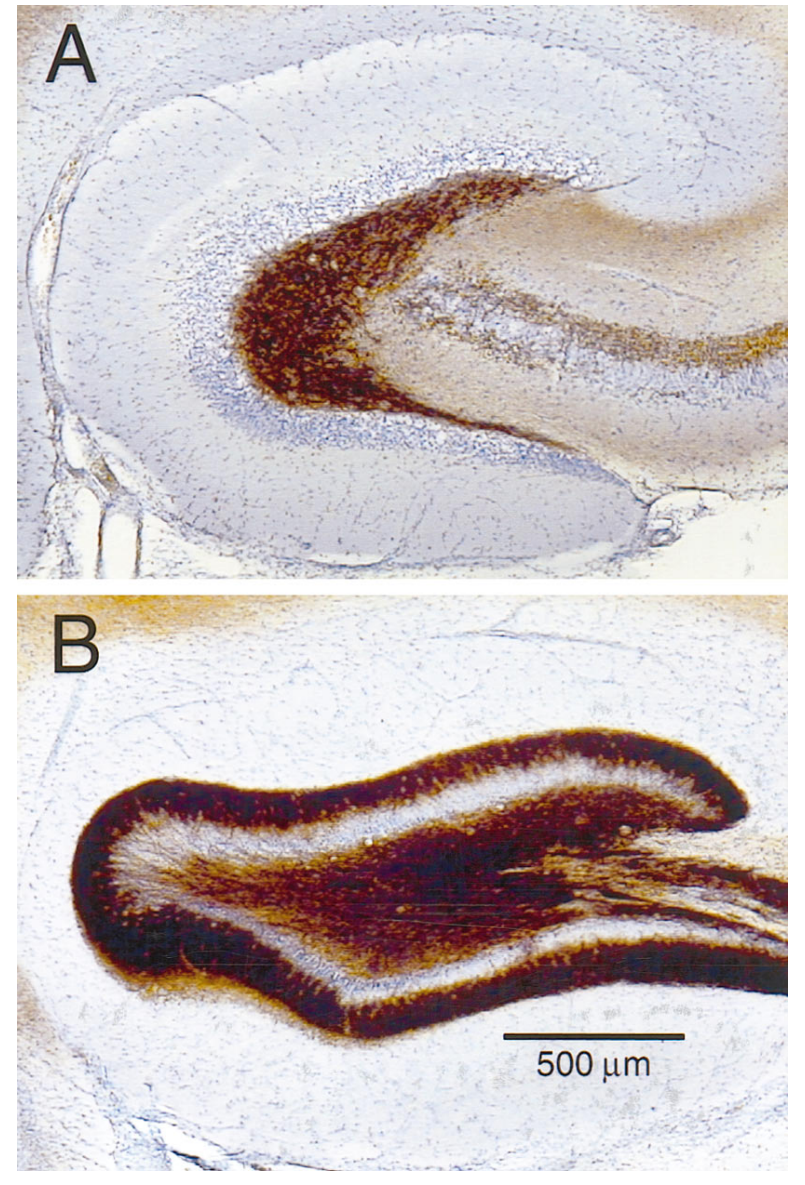

Figure 2. Photomicrographs of the dentate gyrus from a control $(A)$ and a kainate-treated $(B)$ rat. Combined cresyl violet (blue) and Timm's stains (brown) were used to reveal granule cell bodies and mossy fiber boutons simultaneously. In the control slice, Timm's stain labeled the hilar region and mossy fiber projections to the CA3 area. In the slice from the kainate-treated rat $(B)$, Timm's stain also marked a thick band in the inner molecular layer. The data presented in Figure 12, $A$ and $B$, were obtained from the slice in $B$.

intensity resulted in a single population spike in the vast majority of slices; in a few slices, high-intensity stimuli could evoke a second and sometimes a third population spike of small amplitude. Also, slices from kainate-treated rats were obtained shortly (2-4 d) after kainate treatment, at a time when cell loss was established, but before the occurrence of mossy fiber sprouting. The goal of these experiments was to test whether cell loss, in the absence of mossy fiber sprouting, could lead to hyperexcitability in the dentate granule cell layer. Twelve slices from five kainatetreated rats were tested with hilar electrical stimulation in the presence of bicuculline $(10 \mu \mathrm{M})$ and $6 \mathrm{~mm}\left[\mathrm{~K}^{+}\right]_{\mathrm{o}}$. In all slices obtained 2-4 d after kainate treatment, hilar stimulation evoked responses similar to those obtained in slices from control animals (Fig. 3B1-B3).

\section{Antidromic electrical stimulation of granule cells from kainate-treated rats}

A total of 32 slices from 17 kainate-treated rats were tested with antidromic stimulation of the dentate granule cells in the presence of bicuculline $(10 \mu \mathrm{M})$ and elevated extracellular $\left[\mathrm{K}^{+}\right](6 \mathrm{~mm})$. Extracellular field recordings showed bursts of population spikes in response to electrical stimulation of the hilar region in all slices tested from all the kainate-treated rats. Timm's staining revealed

\section{A CONTROL}
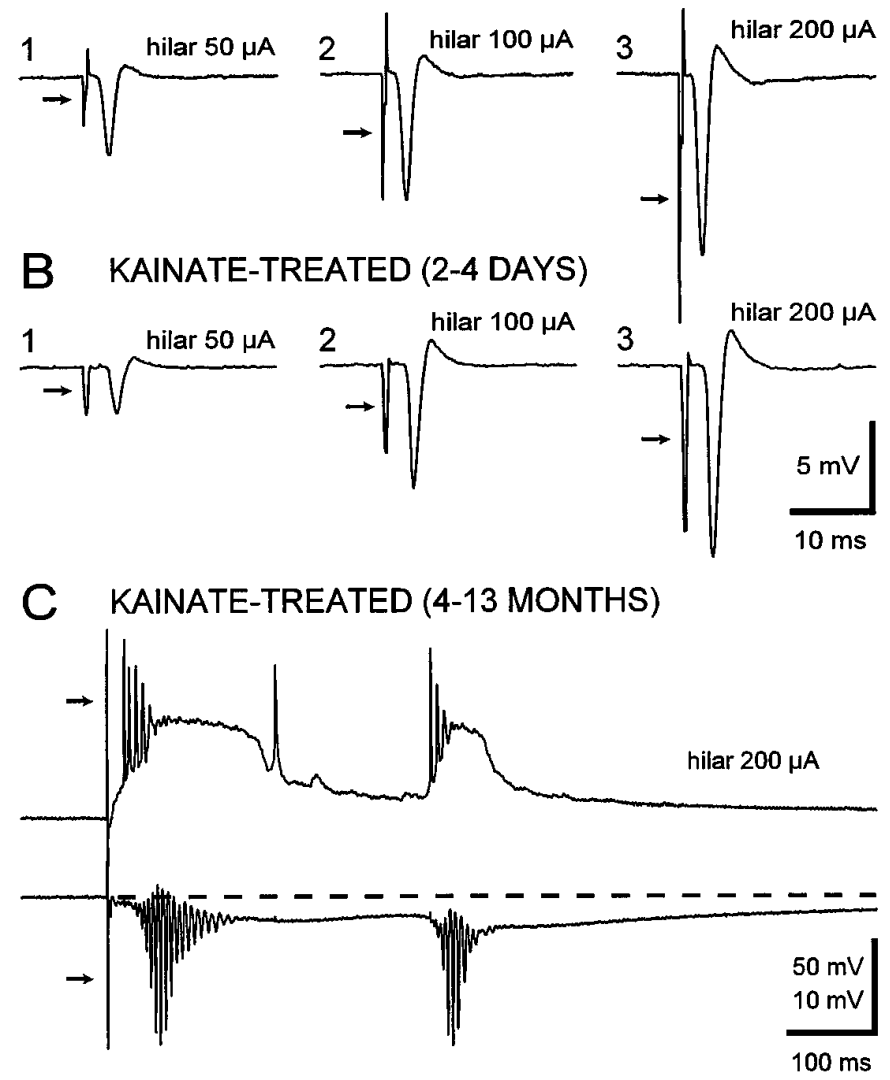

Figure 3. Comparison of electrically evoked responses in the granule cell layer of slices from a control rat $(A)$ and kainate-injected rats $4 \mathrm{~d}(B)$ and 10 months $(C)$ after treatment in $10 \mu \mathrm{M}$ bicuculline and $6 \mathrm{~mm}\left[\mathrm{~K}^{+}\right]_{\mathrm{o}}$. $A 1-A 3, B 1-B 3$, Antidromic (hilar) electrical stimulation evoked one population spike in the granule cell layer. $C$, Antidromic electrical stimulation evoked bursts of action potentials in a granule cell that were synchronized with bursts of population spikes superimposed on long negative shifts. The pairs of traces are simultaneous intracellular (top) and extracellular (bottom) recordings obtained in the outer blade. The extracellular electrode was positioned near the intracellular electrode. The intracellular recording was performed at resting membrane potential $(-73 \mathrm{mV})$. The cell input resistance was $60 \mathrm{M} \Omega$. Composition of the perfusion solution was identical in $A-C$. Arrows show the time of the electrical stimulation. In this and subsequent figures, dashed lines represent baseline.

intense to very intense staining of the inner molecular layer in all of the slices used for the electrophysiological experiments. Simultaneous extracellular and intracellular recordings showed that the bursts of population spikes were synchronized with bursts of action potentials superimposed on long negative shifts (Fig. 3C). Repetitive bursts (Fig. 3C; see also Fig. $4 B$ ) were detected in 21 slices from $13(76 \%)$ kainate-treated rats.

Mossy fiber sprouting has been hypothesized to form excitatory connections between granule cells. If this hypothesis is correct, bursts of EPSPs in granule cells should occur during the extracellular bursts. Furthermore, if repetitive bursts represent successive invasions of a putative excitatory network connecting granule cells, they should be synchronized with EPSPs in granule cells. We detected bursts of EPSPs synchronized with bursts of population spikes in all 47 granule cells recorded in 26 slices from 15 kainatetreated rats (no intracellular recordings were obtained in slices from two kainate-treated rats) (Fig. $4 A$ ). These bursts of EPSPs were observed either at resting membrane potential or with the 

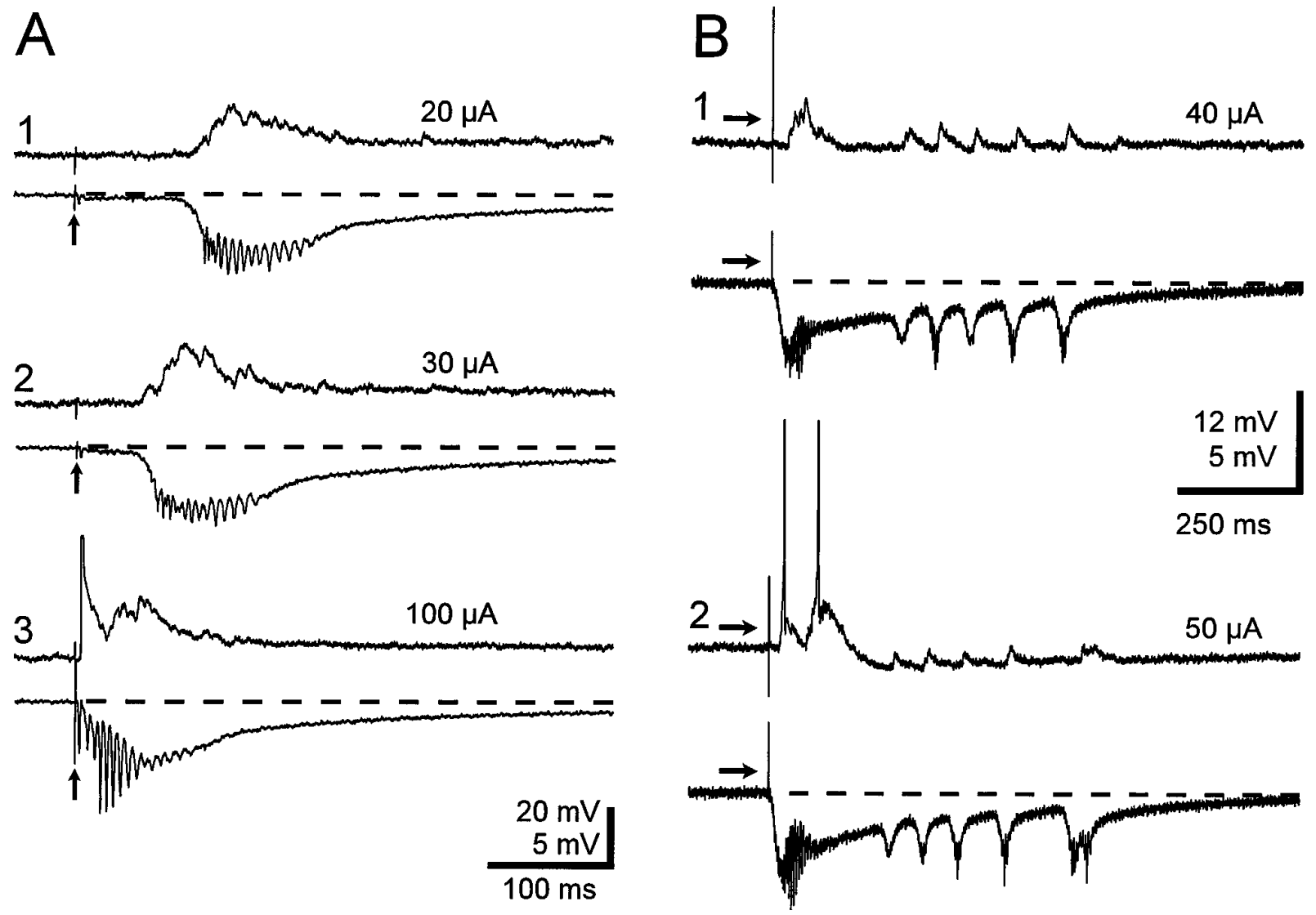

Figure 4. Antidromic (hilar) electrical stimulation of granule cells evoked bursts of EPSPs. $A$, Pairs of traces (1-3) are simultaneous intracellular (top) and extracellular (lower) recordings obtained in the outer blade. The granule cell input resistance was $40 \mathrm{M} \Omega$, and the resting membrane potential was $-70 \mathrm{mV}$. The cell membrane potential was hyperpolarized to $-90 \mathrm{mV}$ with intracellular current injection to block action-potential firing. Note that an antidromic action potential could be evoked with a stimulation intensity of $100 \mu \mathrm{A}$ (3, truncated). Note also the decrease in the delay between the stimulation artifact (arrows) and the beginning of the burst of EPSPs, when the stimulation intensity was increased from $20 \mu \mathrm{A}$ to $30 \mu \mathrm{A}$. $B$, Delayed EPSPs in a granule cell were synchronized with delayed bursts of antidromically evoked population spikes. Top traces $(1,2)$ are intracellular recordings at resting membrane potential $(-68 \mathrm{mV})$ from a granule cell located in the inner blade. Cell input resistance was $100 \mathrm{M} \Omega$. Bottom traces are extracellular recordings obtained also in inner blade. Note the slight delay between the beginning of the extracellular bursts and the rising phase of the EPSPs. Arrows show stimulation artifact.

cell membrane potential hyperpolarized with current injection to block action-potential firing. In 18 granule cells recorded in 16 slices from 13 kainate-treated rats, simultaneous intracellular and extracellular recordings showed that electrical stimulation of the hilar region evoked repetitive EPSPs closely synchronized with repetitive bursts of population spikes (Fig. 4B).

\section{Spontaneous bursting in the dentate gyrus in conditions of reduced inhibition}

Previous studies have shown that in conditions of reduced inhibition, the hippocampal CA3 area bursts spontaneously, but the dentate gyrus does not. This spontaneous bursting has been proposed to be caused by the recurrent excitatory connections between CA3 pyramidal cells (Traub and Wong, 1981, 1982; Miles and Wong, 1983, 1986, 1987; Christian and Dudek, 1988a). If mossy fiber sprouting is functionally similar to the excitatory connections of the CA3 area and tends to increase the excitability of the granule cell population to a level comparable with that of the CA3, one would expect to observe spontaneous bursting in the dentate gyrus when inhibition is depressed. In 13 slices from 9 $(53 \%)$ kainate-treated rats, spontaneous bursting was observed. Seven cells were recorded in seven spontaneously bursting slices from seven kainate-treated rats. Hyperpolarizing the membrane potential of the granule cells blocked action-potential firing and revealed spontaneous bursts of EPSPs synchronized with the extracellular bursting but did not modify the frequency of bursting (Fig. 5). The duration of spontaneous bursts varied between preparations, from $<1 \mathrm{sec}$ (Fig. 5) to several seconds (Fig. 6). The duration of the long spontaneous bursts was critically dependent on the duration of the interburst interval (Fig. 6), suggesting activation of synaptic networks with refractory periods lasting several tens of seconds.

\section{Prolonged seizure-like bursts}

Spontaneous or electrically evoked bursts lasting 2-47 sec were detected in 24 slices from $12(71 \%)$ kainate-treated rats. The average duration of the longest burst measured in each preparation was $9.6 \mathrm{sec}( \pm 2.3, n=17)$. Extracellular recordings of these prolonged bursts were characterized by a large-amplitude negative shift and a change in the bursting pattern of the population spikes from fast and regular firing in the beginning of the burst (resembling the tonic phase of a seizure) to a slower and clustered pattern at the end of the burst (resembling the clonic phase of a seizure) (Fig. 7A). Simultaneous extracellular and intracellular recordings revealed that action-potential firing was synchronized closely with population spike firing throughout the burst (Fig. 7B). 


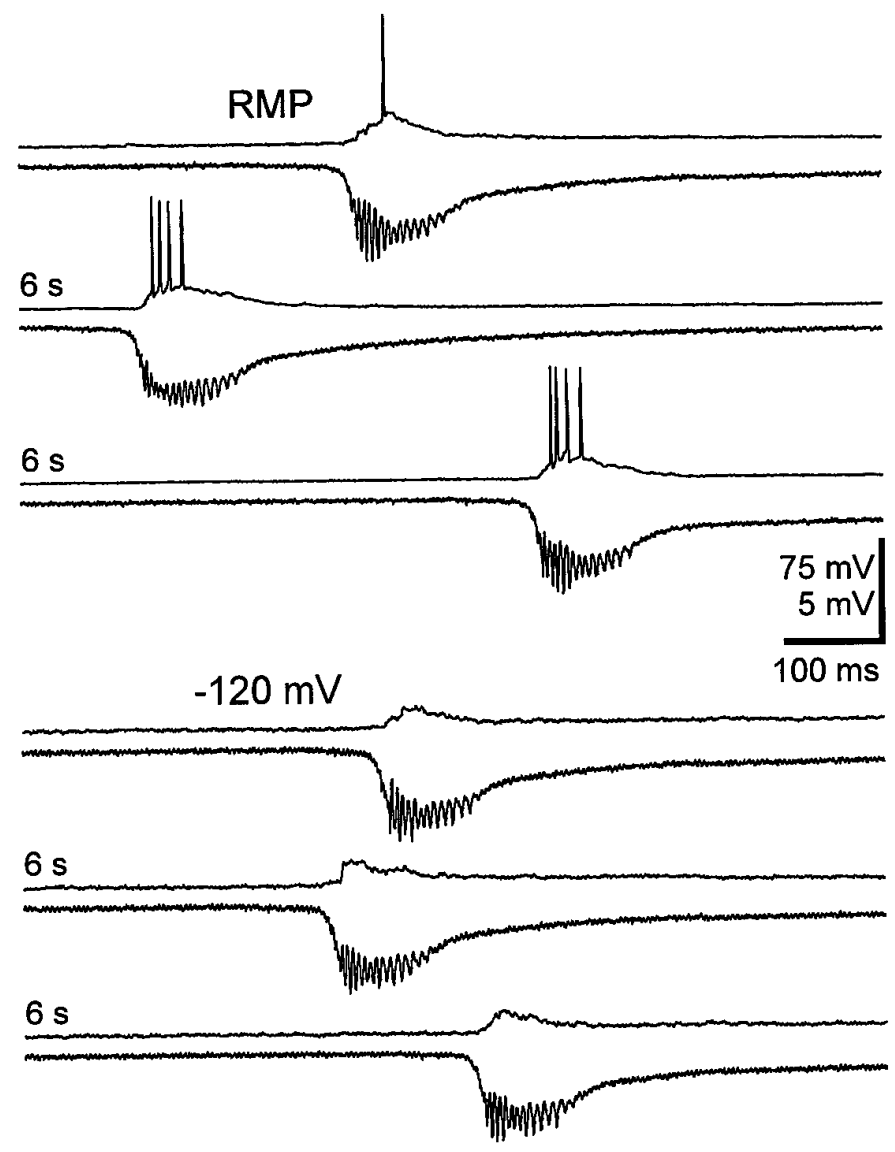

Figure 5. Hyperpolarization of membrane potential with intracellular current injection blocked action-potential firing in a granule cell but did not modify the frequency of the spontaneous bursts. In all panels, top traces are intracellular recordings of a granule cell in the outer blade, and bottom traces are extracellular recordings obtained in the same region. Between each pair of traces, $6 \mathrm{sec}$ periods were deleted during which no activity was detected. Hyperpolarizing the cell membrane potential from resting potential $(-70 \mathrm{mV})$ to $-120 \mathrm{mV}$ blocked action potentials and revealed EPSPs but did not change the spontaneous bursting frequency $(\sim 0.15 \mathrm{~Hz})$. The cell input resistance was $100 \mathrm{M} \Omega$.

To determine whether the changes in firing pattern during prolonged bursts were attributable to a gradual synchronization of a putative excitatory network or to intrinsic properties of granule cells, we examined the intracellular recordings of the long bursts at a high-gain and fast time scale. If the change in firing pattern is attributable to a progressive synchronization of an excitatory synaptic network, changes in the pattern of occurrence of EPSPs should underlie changes in the action-potential firing during the burst. On the other hand, if intrinsic properties of granule cells cause the change in the firing pattern during prolonged bursts (from fast and regular to clustered), firing should not be synchronized with EPSPs. Intracellular recordings of the prolonged bursts revealed that the EPSPs occurred at high frequency at the beginning of the burst and evoked relatively regular firing of action potentials. Later in the burst, summated EPSPs appeared. The amplitude of these EPSPs became progressively larger (i.e., more summated EPSPs) as their frequency decreased. Toward the end of the burst, large depolarization shifts composed of summated EPSPs caused the bursts of action potentials (Fig. 8). Because we used a relatively low dose of bicuculline $(10 \mu \mathrm{M})$, however, we cannot exclude the possibility that some of the synaptic input was

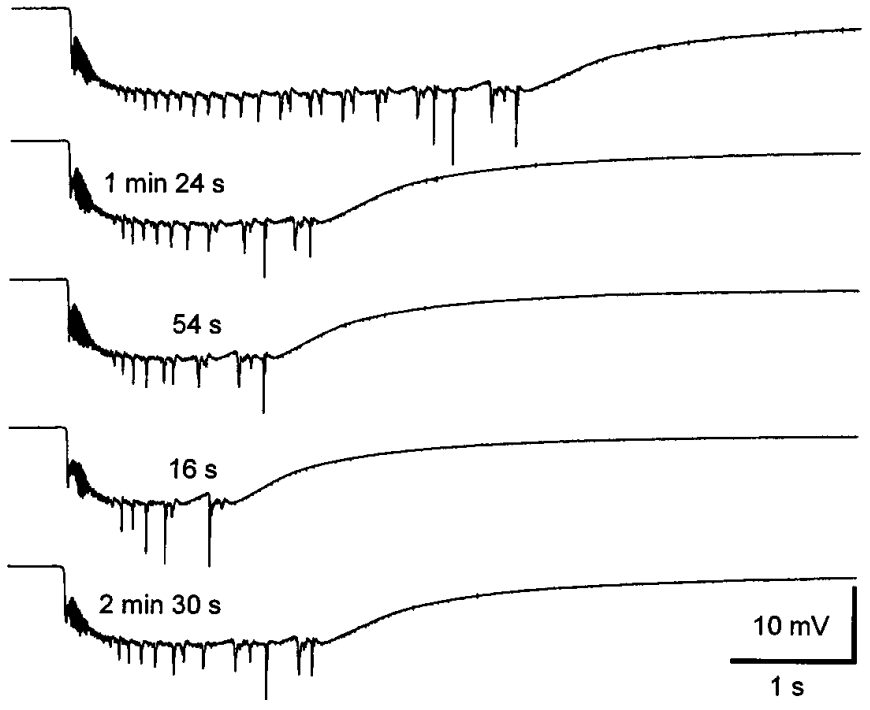

Figure 6. Spontaneous long-duration bursts became shorter when their frequency increased. Traces are extracellular recordings of successive spontaneous bursts obtained with the recording electrode positioned in the apical region of the granule cell layer. Time shown between traces is the time elapsed between the beginning of each successive burst.

from depolarizing IPSPs. Nonetheless, these data suggest that a prolonged increase of the excitatory synaptic input to granule cells, characterized by a progressive synchronization, is responsible for the prolonged bursts observed in hippocampal slices of kainate-treated rats.

\section{Glutamate microstimulation of the granule cell layer}

A total of 19 cells were tested with local glutamate microstimulation of the granule cell layer in 16 slices from seven control rats. Five cells were recorded in the inner blade, eight in the outer blade, and six in the apex. Local applications of glutamate microdrops in the granule cell layer did not evoke a change in EPSP frequency or amplitude of any of the granule cells recorded in slices from control rats.

Mossy fiber sprouting has been hypothesized to represent axon collaterals of granule cells projecting onto other granule cells. To test this hypothesis, we determined whether local glutamate microstimulation of the granule cell layer could increase EPSP frequency and/or amplitude in granule cells close to the stimulation site. Thirty-three granule cells were tested with glutamate microdrops in a total of 18 slices from seven kainate-treated rats. Twenty-one cells (64\%) recorded in 12 slices responded to glutamate microstimulation of the granule cell layer by an abrupt increase of EPSP frequency (Fig. 9). This result suggests that in transverse slices of kainate-treated rats, granule cells are connected together through excitatory circuits.

\section{Characteristics of the glutamate-evoked bursts of EPSPs}

Of the granule cells that showed an increase in EPSP frequency in response to local glutamate microstimulation of the granule cell layer, 10 were recorded in the inner blade of six slices from five preparations, 5 in the outer blade of four slices from three preparations, and 6 in the apex of five slices from five preparations. Responding cells were found in all seven preparations tested. We found no significant difference between the percentage of responsive cells as a function of their location within the granule cell layer: 10 of 14 cells $(71.4 \%)$ tested in the inner blade, 


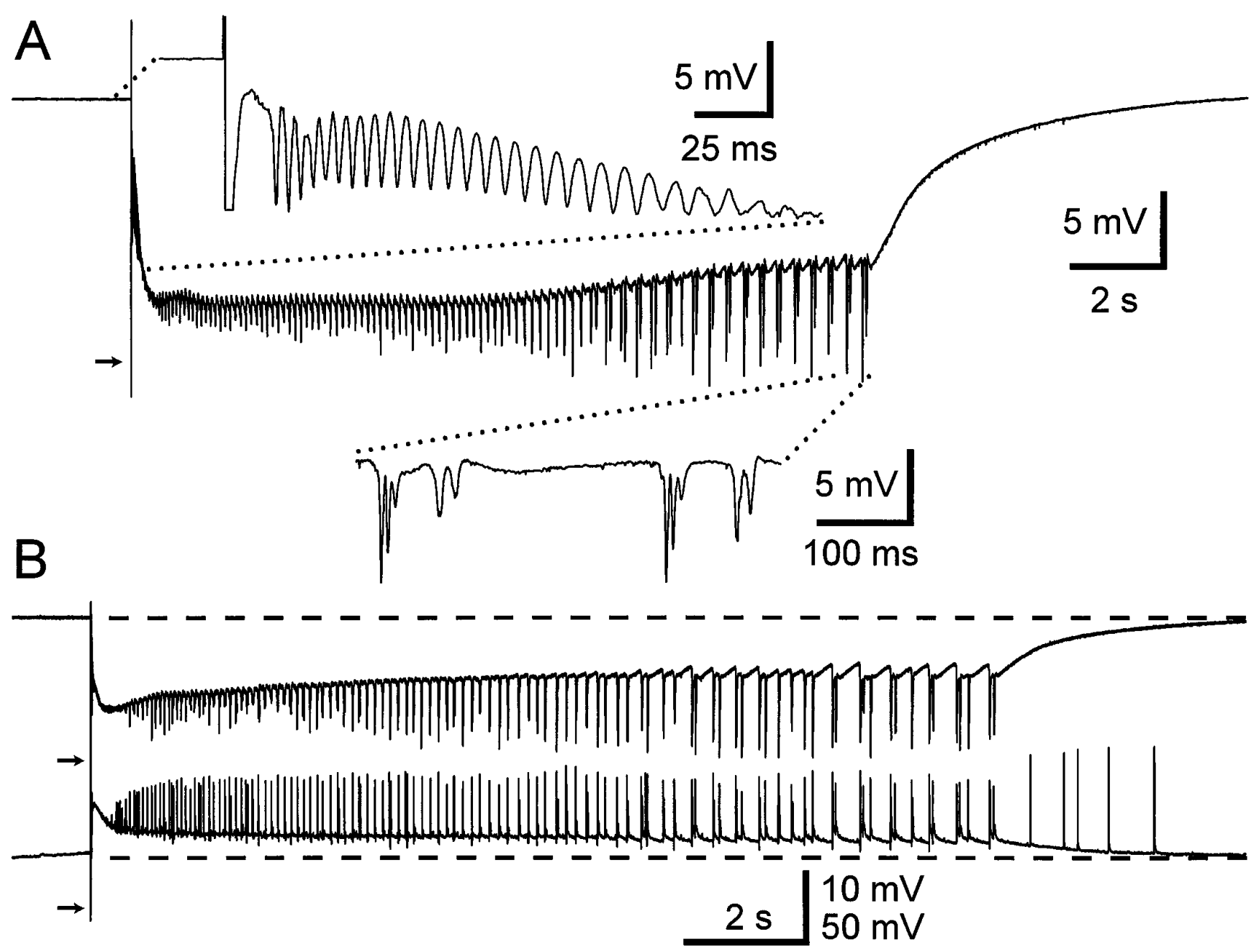

Figure 7. Electrical stimulation of the hilar region could evoke long bursts with tonic and clonic phases. $A$, Evoked burst recorded in the apical region. Note the large amplitude of the negative shift. The insets illustrate the progressive change of the firing pattern of population spikes from fast and regular at the beginning of the burst to slower and clustered at the end of the burst. B, Both extracellular (top) and intracellular (bottom) recordings were obtained in the outer blade of a slice from a different kainate-treated rat. Note the exact synchronization between population spikes and action potentials. Cell resting membrane potential was $-75 \mathrm{mV}$. Stimulus intensity was $100 \mu \mathrm{A}$ in $A$ and $B$ (arrows).

5 of $9(56 \%)$ in the outer blade, and 6 of $10(60 \%)$ in the apex were responsive (Fig. 10A). Twelve cells $(36 \%)$ did not show any change in the EPSPs after local glutamate microstimulation. Four nonresponding cells were located in each of the three regions in nine slices from six kainate-treated preparations.

Granule cells were tested with microdrops of glutamate applied at distances ranging from 50 to $1000 \mu \mathrm{m}$ (Fig. 10B). Although most microdrop applications were within $500 \mu \mathrm{m}$ of the recording electrode, glutamate microstimulation of the granule cell layer applied as far as $1000 \mu \mathrm{m}$ from the recording electrode evoked an increase in EPSPs.

Fourteen granule cells recorded in 12 slices from seven kainatetreated preparations were tested with glutamate microdrops applied in the hilar region. In this group of 14 granule cells, 10 had responded previously to glutamate microstimulation of the granule cell layer by an increase in EPSPs, and 4 had shown no change. Glutamate microdrops applied throughout the hilus did not evoke any change in frequency or amplitude of EPSPs in any of the 14 granule cells tested.

These results support the hypothesis that sprouting forms an excitatory network connecting granule cells throughout the gran- ule cell layer. The degree of connectivity seems to be similar in all areas of the granule cell layer, and it seems to be more dense within $500 \mu \mathrm{m}$ of a given granule cell. We did not detect an excitatory input from hilar cells to granule cells in slices from kainate-treated rats.

\section{Directionality of synaptic connections}

Previous work with glutamate microstimulation in hippocampal slices suggests that local excitatory circuits in the CA3 area may project preferentially from the hilus to the CA2 area (Christian and Dudek, 1988a). By applying glutamate microdrops on both sides of granule cells in slices of kainate-treated rats, we tested the hypothesis that mossy fiber sprouting formed excitatory circuits with no favored direction of projection in transverse hippocampal slices. A total of 22 cells recorded in 16 slices were tested with glutamate microdrops applied on both sides. Eight cells responded by an increase in EPSPs to microstimulation of the dentate gyrus on both sides (Fig. 11), five responded on only one side, and nine did not respond on either side. Thus the excitatory connections between granule cells of kainate-treated rats seem to have no preferential projection in transverse slices. 


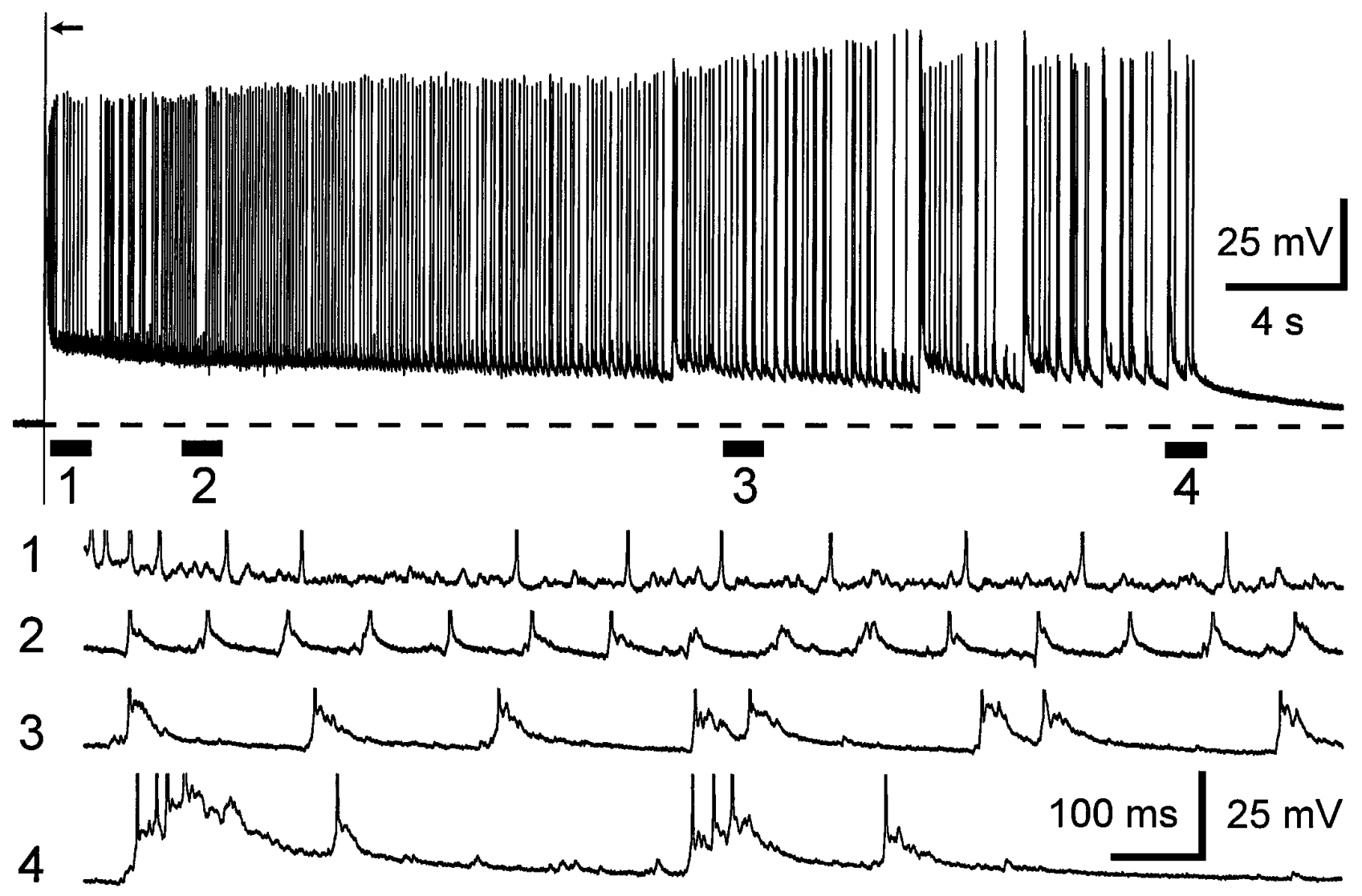

Figure 8. During long bursts, progressively synchronized EPSPs underscored the clustering of the action-potential firing. Intracellular recording of a granule cell located in the inner blade. The thick bars under the top trace show sections enlarged in the bottom traces. Hilar electrical stimulation (arrow) intensity was $250 \mu \mathrm{A}$. Action potentials are truncated in traces $1-4$. Cell input resistance was $80 \mathrm{M} \Omega$; resting membrane potential was $-80 \mathrm{mV}$.

\section{Hyperexcitability and efficacy of glutamate microstimulation}

One implication of the hypothesis that mossy fiber sprouting forms local excitatory circuits leading to hyperexcitability (Tauck and Nadler, 1985) is that a more extensive excitatory network with a higher proportion of granule cells connected through excitatory circuits should result in a more excitable dentate gyrus. Therefore, glutamate microstimulation should evoke an increase of the excitatory input in a higher percentage of granule cells in more excitable slices than in less excitable slices. We defined the level of hyperexcitability by the duration of the burst of population spikes induced by supramaximal antidromic electrical simulation and determined whether there was a correlation between the duration of the extracellular burst and the fraction of granule cells that showed an increase in excitatory input after local glutamate microstimulation. The field-potential recording was obtained, after completion of the intracellular recording and glutamate microstimulation, by placing the extracellular recording electrode at the site where the intracellular recording electrode was positioned previously (Fig. $12 A, B$ ). Glutamate microstimulation produced an increased excitatory input in a much larger percentage of the cells recorded in slices displaying bursts of $>3 \mathrm{sec}$ than in the cells from slices with bursts of $<3 \mathrm{sec}$ (Fig. 12C). Twelve granule cells were tested in four slices with extracellular bursts of $>10 \mathrm{sec} ; 10$ responded to glutamate microstimulation by an increase in EPSPs, and 2 did not show any change. Nine granule cells were tested in four slices with bursts of 3-10 sec; glutamate microdrops evoked an increase of the excitatory input in seven granule cells, and two showed no change. Twelve cells were tested in four slices with bursts of $<1 \mathrm{sec}$. In this group, only four granule cells showed an increase in EPSPs. The distribution of responsive versus nonresponsive cells indicated that the extracellular burst duration was dependent on the proportion of cells that responded to glutamate microstimulation by an increased excitatory input $\left(\chi^{2}=7.6 ; p<\right.$ $0.05 ; \chi^{2}$ test for two independent variables). Thus it seems that there is a correlation between the occurrence of seizure-like events in the dentate gyrus of hippocampal slices with mossy fiber sprouting and a high proportion of granule cells connected through excitatory circuits.

\section{DISCUSSION}

The first main result from these studies is that antidromic stimulation of dentate granule cells in hippocampal slices from kainatetreated rats with robust mossy fiber sprouting evoked prolonged seizure-like bursts of action potentials when $\mathrm{GABA}_{\mathrm{A}}$ receptormediated inhibition was decreased with bicuculline and membrane excitability was increased with $6 \mathrm{~mm}\left[\mathrm{~K}^{+}\right]_{\mathrm{o}}$. Under identical conditions, antidromic stimulation of granule cells in slices from control rats or kainate-treated rats without mossy fiber sprouting (i.e., 2-4 d after treatment) did not evoke bursts. The second main result is that local glutamate stimulation induced robust increases in the frequency of EPSPs in adjacent granule cells in slices with mossy fiber sprouting but not in slices without mossy fiber sprouting. The prolonged seizure-like activity and the increases in EPSP frequency caused by glutamate microstimulation were observed in slices from kainate-injected rats several months after the actual 

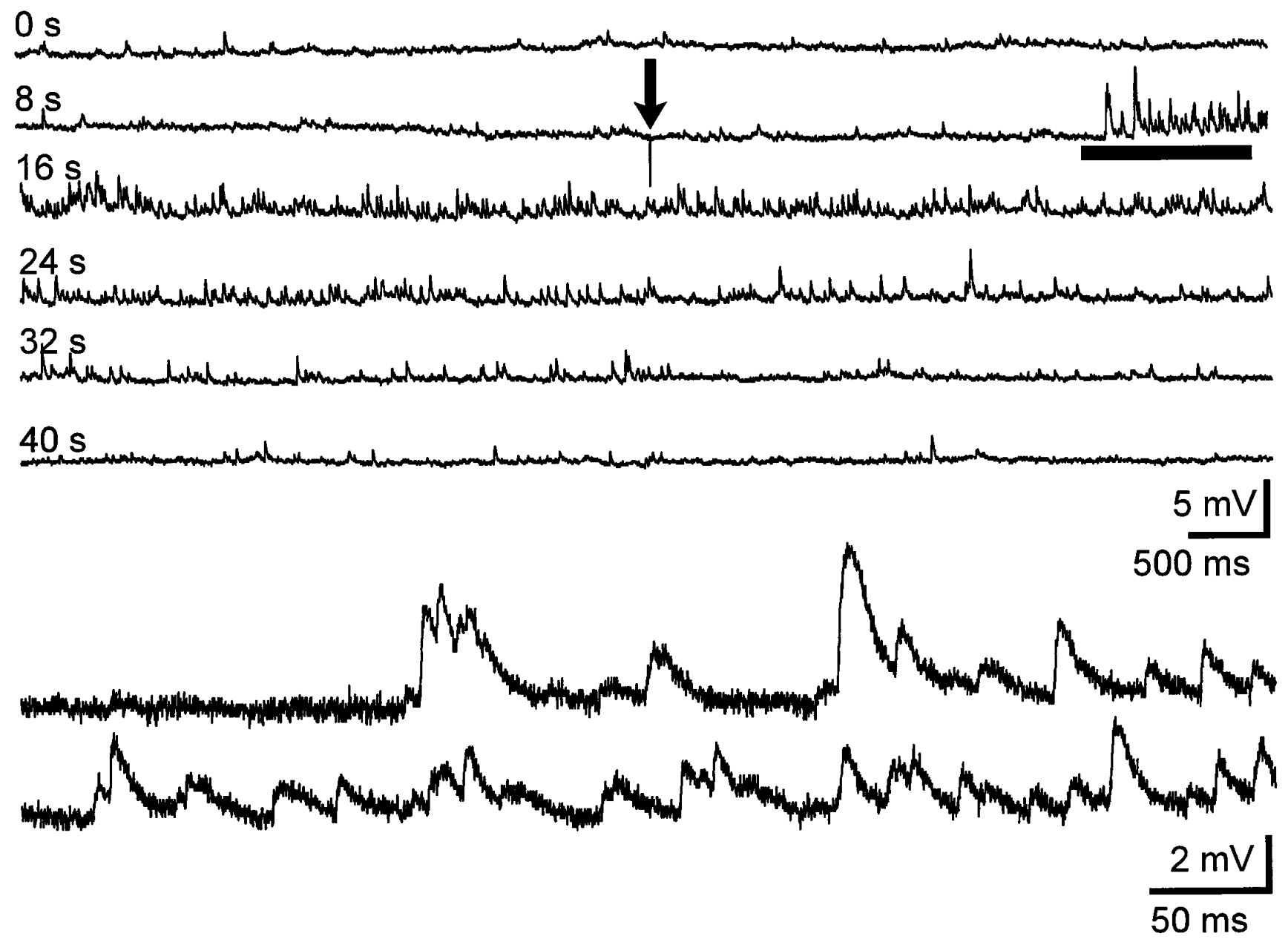

Figure 9. Glutamate microstimulation of the granule cell layer evoked an abrupt increase of EPSP size and frequency in a granule cell. Intracellular recording of a granule cell located in the inner blade is shown at resting membrane potential $(-73 \mathrm{mV})$ while a glutamate microdrop was applied 250 $\mu \mathrm{m}$ from the recorded cell toward the side of the tip of the inner blade. Arrow shows the artifact produced by the microdrop touching the slice. Time indicates the beginning of each trace. Traces are consecutive. The bottom traces are an enlargement of the area underlined by the thick bar. Cell input resistance was $80 \mathrm{M} \Omega$.

treatment and at a time when the animals were known to be having spontaneous epileptic seizures. The seizure-like activity seemed to have both tonic and clonic phases, and it lasted from several seconds to nearly $1 \mathrm{~min}$. Not only were robust trains of EPSPs evoked by antidromic stimulation of the mossy fibers in the hilus, but selective microstimulation of granule cells, even hundreds of micrometers away from the recorded granule cell, routinely evoked long trains of EPSPs. The close association between the occurrence of glutamate-evoked EPSPs and the prolonged seizure-like discharges, along with the observation that the action potentials during the seizure-like discharges were triggered by large EPSPs, strongly supports the hypothesis that new recurrent excitatory synaptic connections generate these epileptiform events.

A critical concept relevant to these studies is that recurrent excitation can provide positive feedback in a neural network only under certain conditions. First, action potentials must propagate from neuron to neuron, which requires that individual neurons have a resting membrane potential close to firing threshold; therefore, we conducted these experiments in $6 \mathrm{~mm}\left[\mathrm{~K}^{+}\right]_{\mathrm{o}}$. Second, recurrent inhibition can block multisynaptic interactions mediated by local excitatory circuits (Dichter and Spencer, 1969a,b; Miles and Wong, 1983, 1986, 1987; Miles et al., 1984; Christian and Dudek, 1988a,b), so we performed these studies in the presence of the $\mathrm{GABA}_{\mathrm{A}}$-receptor antagonist bicuculline. We confirmed that these two treatments in themselves do not lead to prolonged seizure-like activity in the dentate gyrus of control animals (Fricke and Prince, 1984; Cronin et al., 1992). Therefore, we hypothesized that if granule cells were connected through new recurrent excitatory circuits, these conditions would allow firing activity in granule cells to propagate to other granule cells and thus lead to the explosive positive feedback necessary for generating prolonged seizure-like activity. To illustrate this concept, an analogy can be made by comparing the CA3 to the CA1 areas of the hippocampus. When inhibition is present, the responses to extracellular electrical stimulation are quite similar in the two cell populations, even though CA3 pyramidal cells are known to have more recurrent excitatory circuits than the CA1 area (Christian and Dudek, 1988a,b; Amaral and Witter, 1989). When GABA receptor-mediated inhibition is blocked pharmacologically, however, the CA3 pyramidal cells generate robust network-driven bursts of activity (Prince, 1985; Korn et al., 1987; Traynelis and Dingledine, 1988), whereas the CA1 pyramidal cells have small graded bursts (Miles et al., 1984; Meier et al., 1992). Thus, the 

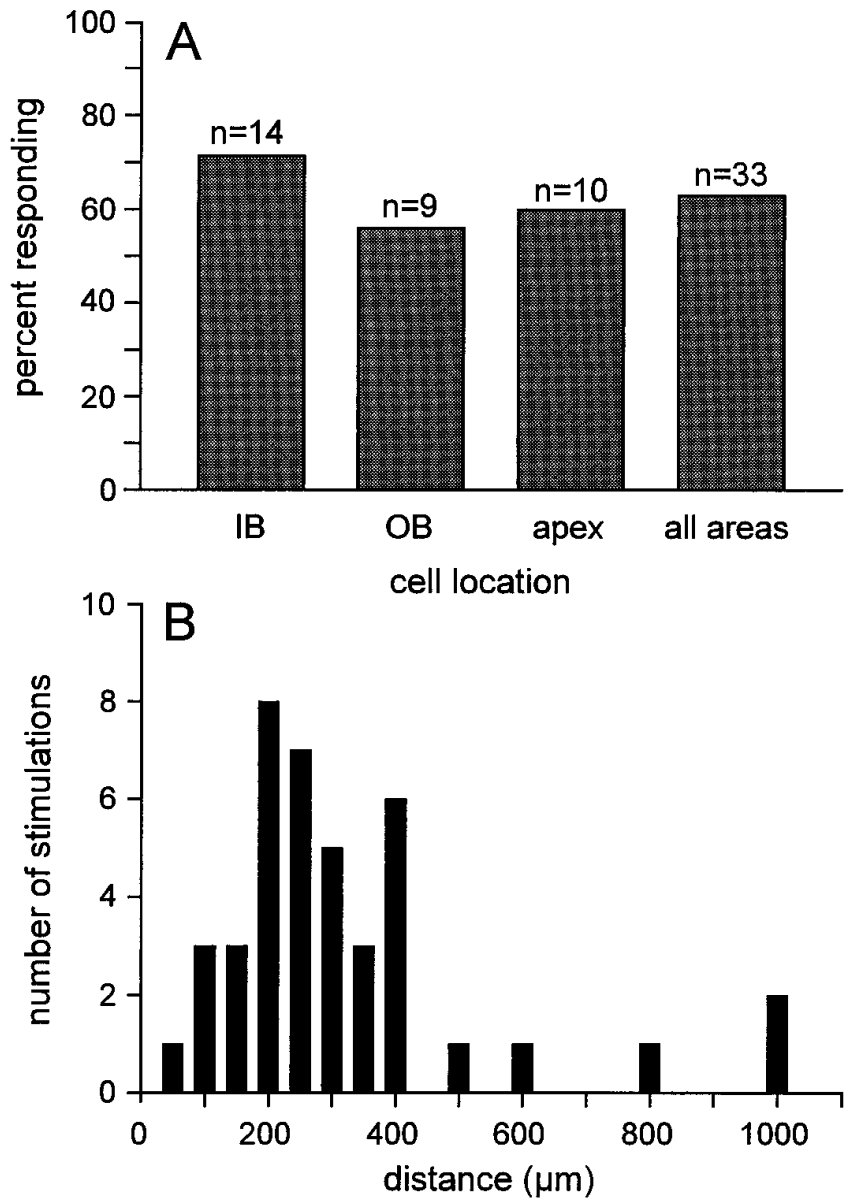

Figure 10. A, Plot of the percentage of cells responding to glutamate microstimulation by an increase in EPSPs as a function of their location in the granule cell layer. All of the granule cells tested with microapplications of glutamate were grouped according to the arbitrarily defined region where they were located: inner blade $(I B)$, outer blade $(O B)$, and apical region (apex). B, Histogram of the distances between granule cells and glutamate microstimulations. The distance was measured between the point of entry of the recording electrode in the slice and the application site of the glutamate microdrop. The number of stimulations $(n=41)$ includes only one application for a given distance in each side of the granule cell and therefore excludes repeated applications of the same site.

presence of mossy fiber sprouting seems to transform the dentate granule cells from a neural network similar to CA1 to one like CA3.

The results provided here suggest that the dentate gyrus of these kainate-treated rats with mossy fiber sprouting became epileptogenic. In particular, the dentate granule cells of these epileptic animals showed an increased susceptibility to the generation of epileptiform activity, and they were capable of producing seizure-like bursts independent of synaptic input from other structures. These seizure-like events occurred in hippocampal slices without the entorhinal cortex and could be evoked with antidromic stimulation, thus indicating that the epileptogenesis was intrinsic to the dentate gyrus and did not require extrinsic synaptic input. Kainate treatment damaged the CA3 area extensively, but we cannot exclude the possibility that in conditions of reduced inhibition, spontaneous bursts in the CA3 may have influenced activity in the dentate granule cell layer. The observation that these events occur only months after kainate treatment, but not 2-4 d after treatment, supports the hypothesis that sprouting must be established before epilepsy can occur, and thus underscores the

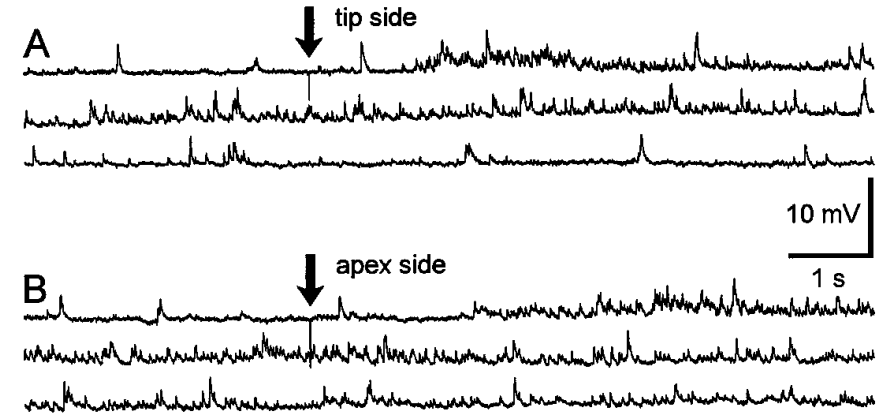

Figure 11. Glutamate microstimulations of areas in both sides of a granule cell evoked an increase in EPSP frequency. The distance between glutamate microdrop and recording electrode was $200 \mu \mathrm{m}$ in $A$ and 250 $\mu \mathrm{m}$ in $B$. The cell was located in the inner blade. Cell input resistance was $50 \mathrm{M} \Omega$; resting membrane potential was $-80 \mathrm{mV}$. Traces are consecutive in $A$ and $B$. Arrows show the artifact produced by the microdrops touching the slice.

critical role of mossy fiber sprouting in the epileptogenicity of the dentate gyrus. This delay between kainate treatment and epilepsy in rats parallels the latency of weeks to months between the initial neuronal injury (e.g., status epilepticus, stroke, and head injury) and the beginning of the occurrence of generalized seizures in epileptic patients. This seizure-free "latent" period is a prominent characteristic of clinical epilepsy.

Experiments with hilar electrical stimulation strongly support the hypothesis that new recurrent excitatory circuits have formed in kainate-treated rats with mossy fiber sprouting. They also confirm and extend the earlier observations that hilar stimulation evoked EPSPs with long and variable latency, which suggested that the granule cell network was interconnected with recurrent excitatory connections (Cronin et al., 1992). The key new result, however, was the observation that glutamate microstimulation in the granule cell body layer evoked EPSPs in granule cells. This approach was based on earlier studies on CA3 and CA1 pyramidal cells (Christian and Dudek, 1988a,b). Glutamate microstimulation was shown previously to activate selectively the somatodendritic region of granule and pyramidal cells in the hippocampus, but not to initiate action potentials when applied to axons. In particular, glutamate microdrops applied in the CA3 area evoked trains of EPSPs when GABA $_{\mathrm{A}^{-}}$-receptor-mediated inhibition was blocked with picrotoxin; substantially fewer responses were evoked in the CA1 area, particularly in longitudinal slices. These results are consistent with studies using dual intracellular recording techniques to study recurrent excitation in these areas (Knowles and Schwartzkroin, 1981; Miles and Wong 1986, 1987; Nakajima et al., 1991). In the present study, glutamate microstimulation in hippocampal slices with mossy fiber sprouting routinely evoked EPSPs in granule cells, and the stimulation was effective at many sites in the granule cell layer, thus suggesting that the granule cells were widely interconnected. On the other hand, glutamate microstimulation in the hilus did not evoke robust increases in EPSP frequency or amplitude. These electrophysiological data are consistent with ultrastructural studies in animal models and human tissue from temporal lobe epilepsy surgeries indicating that new mossy fiber synapses are made onto dendritic spines in the inner molecular layer (Wenzel et al., 1995; Zhang and Houser, 1995), which presumably belong to dentate granule cells, because basket cells have few if any dendritic spines. Other studies have suggested, on the basis of indirect data (in vivo extracellular recordings and light microscopic observations), that 

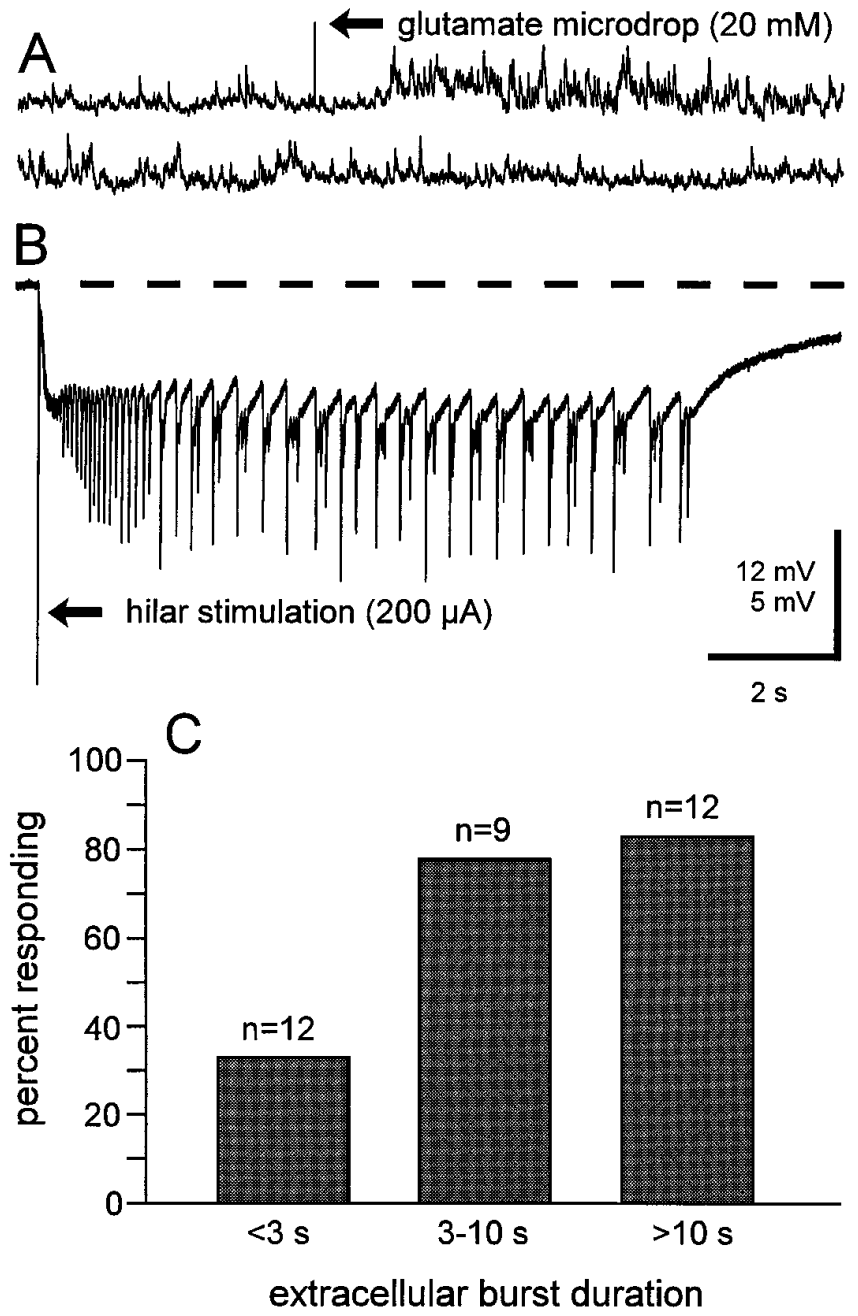

Figure 12. Local glutamate microstimulation evoked an increase of the excitatory input in a higher percentage of granule cells in slices showing long antidromically evoked bursts. $A$, A granule cell located in the outer blade showed an increase in EPSPs in response to a glutamate microdrop applied $400 \mu \mathrm{m}$ from the recording electrode in the side of the tip of the outer blade (slice shown in Fig. 2B). $B$, After removal of the intracellular recording electrode, an extracellular recording electrode was positioned in the same region, and antidromic (hilar) electrical stimulation evoked a long burst. The cell input resistance was $50 \mathrm{M} \Omega$, and resting membrane potential was $-82 \mathrm{mV}$. $C$, Plot of the percentage of cells responding to glutamate microstimulation by an increase in EPSPs as a function of the duration of the antidromically evoked extracellular burst. For each granule cell tested with glutamate microstimulations, extracellular burst recordings were obtained in the same area. All of the granule cells tested were grouped in three categories depending on the duration of the extracellularly recorded burst: $<3 \mathrm{sec}, 3-10 \mathrm{sec}$, and $>10 \mathrm{sec}$.

new mossy fiber axons in the inner molecular layer of kainatetreated rats form excitatory synapses on inhibitory basket cells, which would thus have restorative and not epileptogenic effects (Sloviter, 1992). Because all of the data in the present study were obtained in bicuculline, our experiments do not rule out the possibility that mossy fiber axons also make synapses on basket cells in the inner molecular layer.

One question that deserves further consideration is the degree to which the electrophysiological abnormalities observed in this study could contribute to the generalized behavioral seizures we and others have observed in kainate-treated rats. Although all of the animals used in these experiments had many generalized seizures, one cannot conclude that mossy fiber sprouting in the dentate gyrus actually triggered these seizures and motor convulsions. Similar forms of synaptic reorganization through axonal sprouting could occur in other cortical structures. It has been proposed to occur in the CA1 area of the hippocampus of kainatetreated rats (Meier and Dudek, 1993). Therefore, the hypothesis can be proposed that axonal reorganization occurs in many cortical areas after neuronal damage, and thus generalized seizures may originate in one site or in a number of sites characterized by abnormal recurrent excitatory circuits.

The most parsimonious interpretation of our data is that the dentate gyrus of kainate-treated rats with mossy fiber sprouting has an increased seizure susceptibility. When $\mathrm{GABA}_{\mathrm{A}}$-receptormediated inhibition is blocked pharmacologically and membrane excitability is increased in $6 \mathrm{~mm}\left[\mathrm{~K}^{+}\right]_{\mathrm{o}}$, direct stimulation of granule cells leads to robust seizure-like activity, which seems to be dependent on new recurrent excitatory synapses. The weeks, months, and even years required for extensive synaptic reorganization (e.g., mossy fiber sprouting) to occur in human cortex could account for the latent period known to occur in lesion-induced epilepsy. The presence of normal (or even enhanced) synaptic inhibition could explain the large proportion of time during which seizures do not occur in the epileptic brain; the intermittent occurrence of seizures could be triggered by a combination of intense synaptic excitation and decreased synaptic inhibition in an area that has undergone synaptic reorganization. This general hypothesis, which can account for many of the properties of lesion-induced epilepsy, can be tested both in animal models and in human tissue from temporal lobe epilepsy surgeries.

\section{REFERENCES}

Amaral DG, Witter MP (1989) The three-dimensional organization of the hippocampal formation: a review of anatomical data. Neuroscience 31:571-591.

Babb TL, Kupfer WR, Pretorius JK, Crandall PH, Levesque MF (1991) Synaptic reorganization by mossy fibers in human epileptic fascia dentata. Neuroscience 42:351-363.

Ben-Ari Y (1985) Limbic seizure and brain damage produced by kainic acid: mechanisms and relevance to human temporal lobe epilepsy. Neuroscience 14:375-403.

Christian EP, Dudek FE (1988a) Characteristics of local excitatory circuits studied with glutamate microapplication in the CA3 area of rat hippocampal slices. J Neurophysiol 59:90-109.

Christian EP, Dudek FE (1988b) Electrophysiological evidence from glutamate microapplications of local excitatory circuits in the CA1 area of rat hippocampal slices. J Neurophysiol 59:110-123.

Cronin J, Obenaus A, Houser CR, Dudek FE (1992) Electrophysiology of dentate granule cells after kainate-induced synaptic reorganization of the mossy fibers. Brain Res 573:305-310.

de Lanerolle NC, Kim JH, Robbins RJ, Spencer DD (1989) Hippocampal interneuron loss and plasticity in human temporal lobe epilepsy. Brain Res 495:387-395.

Dichter M, Spencer WA (1969a) Penicillin-induced interictal discharges from the cat hippocampus. I. Characteristics and topographical features. J Neurophysiol 32:649-662.

Dichter M, Spencer WA (1969b) Penicillin-induced interictal discharges from the cat hippocampus. II. Mechanisms underlying origin and restriction. J Neurophysiol 32:663-687.

Franck JE (1993) Cell death, plasticity, and epilepsy: insights provided by experimental models of hippocampal sclerosis. In: Epilepsy, models, mechanisms, and concepts (Schwartzkroin P, ed), pp 281-304. Cambridge: Cambridge UP.

Fricke RA, Prince DA (1984) Electrophysiology of dentate gyrus granule cells. J Neurophysiol 51:195-209.

Haas HL, Schaerer B, Vosmansky M (1979) A simple perfusion chamber for the study of nervous tissue slices in vitro. J Neurosci Methods $1: 323-325$. 
Houser CR (1992) Morphological changes in the dentate gyrus in human lobe epilepsy. In: The dentate gyrus and its role in seizures (Ribak CE, Gall CM, Mody I, eds), pp 223-234. Amsterdam: Elsevier.

Knowles WD, Schwartzkroin PA (1981) Local circuit synaptic interactions in hippocampal brain slices. J Neurosci 1:318-322.

Korn SJ, Giacchino JL, Chamberlain NL, Dingledine R (1987) Epileptiform burst activity induced by potassium in the hippocampus and its regulation by GABA-mediated inhibition. J Neurophysiol 57:325-340.

Larner AJ (1995) Axonal sprouting and synaptogenesis in temporal lobe epilepsy: possible pathogenetic and therapeutic roles in neurite growth inhibitory factors. Seizure 4:249-258.

Margerison JH, Corsellis JAN (1966) Epilepsy and the temporal lobes: a clinical, electroencephalographic and neuropathological study of the brain in epilepsy, with particular reference to the temporal lobes. Brain 89:499-536.

Meier CL, Dudek FE (1993) Spontaneous and stimulation-induced synchronized afterdischarges in the isolated CA1 of kainate-treated rats. Soc Neurosci Abstr 33:1464.

Meier CL, Obenaus A, Dudek FE (1992) Persistent hyperexcitability in isolated hippocampal CA1 of kainate-lesioned rats. J Neurophysiol 68:2120-2127.

Miles R, Wong RKS (1983) Single neurones can initiate synchronized population discharge in the hippocampus. Nature 306:371-373.

Miles R, Wong RKS (1986) Excitatory synaptic interactions between CA3 neurones in the guinea-pig hippocampus. J Physiol (Lond) 373:397-418.

Miles R, Wong RKS (1987) Inhibitory control of local excitatory circuits in the guinea pig hippocampus. J Physiol (Lond) 388:611-629.

Miles R, Wong RKS, Traub RD (1984) Synchronized afterdischarges in the hippocampus: contribution of local synaptic interactions. Neuroscience 12:1179-1189.

Nadler JV (1981) Kainic acid as a tool for the study of temporal lobe epilepsy. Life Sci 29:2031-2042.

Nakajima S, Frank JE, Bilkey D, Schwartzkroin PA (1991) Local circuit synaptic interactions between CA1 pyramidal cells and interneurons in the kainate-lesioned hyperexcitable hippocampus. Hippocampus 1:67-78.

Prince DA (1985) Physiological mechanisms of focal epileptogenesis. Epilepsia 26:S3-S14.

Racine RJ (1972) Modification of seizure activity by electrical stimulation. II. Motor seizure. Electroencephalogr Clin Neurophysiol 32:281-294.

Represa A, Niquet J, Pollard H, Ben-Ari Y (1994) Cell death, gliosis, and synaptic remodeling in the hippocampus of epileptic rats. J Neurobiol 26:413-425.

Sloviter RS (1992) Possible functional consequences of synaptic reorganization in the dentate gyrus of kainate-treated rats. Neurosci Lett 137:91-96.

Sperk G (1994) Kainic acid seizures in the rat. Prog Neurobiol 42:1-32.

Sutula T, Cascino G, Cavazos J, Parada I, Ramirez L (1989) Mossy fiber synaptic reorganization in the epileptic human temporal lobe. Ann Neurol 26:321-330.

Tauck DL, Nadler JV (1985) Evidence of functional mossy fiber sprouting in hippocampal formation of kainic acid-treated rats. J Neurosci 5:1016-1022.

Traub RD, Wong RKS (1981) Penicillin-induced epileptiform activity in the hippocampal slice: a model of synchronization in epilepsy. Neuroscience 6:223-230.

Traub RD, Wong RKS (1982) Cellular mechanism of neuronal synchronization in epilepsy. Science 216:745-747.

Traynelis SF, Dingledine R (1988) Potassium-induced spontaneous electrographic seizures in the rat hippocampal slice. J. Neurophysiol. 59:259-276.

Wenzel HJ, Wooley CS, Schwartzkroin PA (1995) Kainic acid-induced mossy fiber sprouting and synapse formation in the rat dentate gyrus. Soc Neurosci Abstr 21:1472.

Zhang N, Houser CR (1995) Dynorphin immunoreactivity in the dentate gyrus in human temporal lobe epilepsy: an electron microscopic study of reorganized mossy fiber synapses. Soc Neurosci Abstr 21:1962. 